\title{
Sulphate record from a northeast Greenland ice core over the last 1200 years based on continuous flow analysis
}

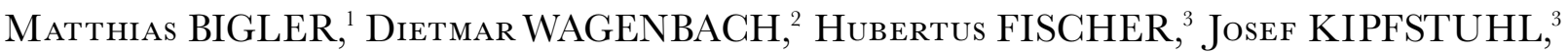 \\ Heinrigh MILLER, ${ }^{3}$ Stefan SOMMER, ${ }^{1}$ Bernhard STAUFFER ${ }^{1}$ \\ ${ }^{1}$ Climate and Environmental Physics, Physics Institute, University of Bern, Sidlerstrasse 5, CH-3012 Bern, Switzerland \\ E-mail:bigler@climate.unibe.ch \\ ${ }^{2}$ Institut für Umweltphysik, University of Heidelberg, Im Neuenheimer Feld 229, D-69120 Heidelberg, Germany \\ ${ }^{3}$ Alfred Wegener Institute for Polar and Marine Research, Columbusstrasse, D-27515 Bremerhaven, Germany
}

\begin{abstract}
A $150 \mathrm{~m}$ deep ice core from the low-accumulation area of northeast Greenland was analyzed for sulphate, calcium, sodium and electrolytical meltwater conductivity at a depth resolution of approximately $1 \mathrm{~cm}$ by continuous flow analysis (CFA). The calcium and sodium profiles are used to establish a relatively precise ice-core chronology by annual-layer counting back to AD 830. Inspection of the novel CFA method for sulphate revealed relative errors typically around $15 \%$, but at least $\pm 20 \mathrm{ng} \mathrm{g}^{-1}$, for concentrations $<130 \mathrm{ng} \mathrm{g}^{-1}$, and a current detection limit for routine ice-core analyses of $40 \mathrm{ng} \mathrm{g}^{-1}$. Annual sulphate peaks are shown to occur over almost the entire core, with only a small shift in seasonality between the modern and pre-industrial sections. Inspection of volcanic horizons allowed more accurate timing of these peaks and clear identification of calcium-rich events. Disregarding clear volcanic peaks, significant long-term changes of sulphate are only seen over the industrial period. However, a higher frequency of important volcanic inputs was identified around AD 1200.
\end{abstract}

\section{INTRODUCTION}

Sulphate components constitute a major part of the submicron aerosol body and thus contribute significantly to direct and indirect aerosol radiative forcing. While ice-core studies clearly show that anthropogenic sulphur-dioxide emission controls the modern sulphate budget of the Northern Hemisphere (Neftel and others, 1985; Mayewski and others, 1990; Fischer and others, 1998b), much less is known about the natural sulphate source apportionment (mainly with respect to marine dimethyl sulphide, soil dust, sea salt and volcanoes) and about the possible long-term sulphate variability during the pre-industrial era. For sulphate, glaciochemical ice-core studies from Greenland have been evaluated in detail mainly over the last 200 years (with only few records available back to 500 years (e.g. Fischer and others, 1998b)). Time series from the Greenland Summit exist over the entire Holocene (and beyond) in up to biannual (Mayewski and others, 1997) and in small sections at seasonal resolution (Legrand and others, 1997). They were examined, however, mainly in view of strong volcanic inputs (Zielinski and others, 1994; Zielinski, 1995) or Holocene/Pleistocene changes of atmospheric sulphur species (Legrand and others, 1997). Here we report on detailed continuous high-resolution sulphate analyses on an ice core from northeast Greenland going back to approximately AD 830. This record covers both the Little Ice Age and the Medieval Warming. Evaluation of our dataset, which stands out as the first long-term sulphate record in sub-seasonal resolution, is mainly aimed at: (1) assessment of the reliability of the newly applied continuous flow analyses (CFA) for sulphate (even at relatively low levels), (2) the deployment of our high-resolution sulphate record for the examination of distinct peaks such as volcanic horizons made up by $\mathrm{H}_{2} \mathrm{SO}_{4}$, and (3) inspection of the last 1200 year period for possible long-term perturbation in the background sulphate level.

\section{METHODS}

\section{Sample collection and processing}

Within the North Greenland Traverse (NGT) project, 13 ice cores covering mainly the last 500 years were drilled, along with numerous shallow firn cores and snow-pit samplings (Fischer and others, 1998a). To use the potential of the high depth resolution of the CFA system, we selected one of the deeper cores $(150 \mathrm{~m})$ situated in the less explored low-accumulation area of northeast Greenland, hereafter denoted as B20 ( $78^{\circ} 50^{\prime} \mathrm{N}, 36^{\circ} 30^{\prime} \mathrm{W}$; $2150 \mathrm{~m}$ a.s.l.). For the geographical position of B20 in relation to other drill sites see Figure 1.

Core sections, $3 \times 3 \mathrm{~cm}^{2}$ and $110 \mathrm{~cm}$ long, were transported to the Bern laboratory where they were continuously melted on a special firn melt head (Röthlisberger and others, 2000), as an important part of the core consists of porous firn. The uncontaminated meltwater from the central part of the melt head, which has not been exposed to the ambient atmosphere, was permanently drained off, debubbled and split into nine substreams at a flow rate of $0.9 \mathrm{~mL} \mathrm{~min}^{-1}$ each for concurrent online chemical analyses by CFA.

\section{Chemical analyses}

For the chemical measurements, a CFA system was used as described in detail by Röthlisberger and others (2000). It essentially consists of fluorescence or absorption spectrometric detection systems for sulphate, nitrate, calcium, 


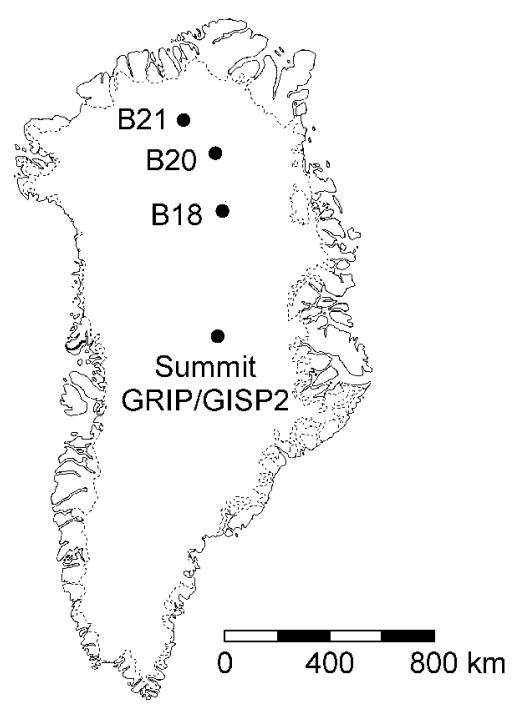

Fig. 1. Geographical position of the B20 ice core in relation to other NGT drill sites and Summit.

sodium, ammonium and hydrogen peroxide. In addition, the electrolytical meltwater conductivity was measured continuously as an estimate for the total ion concentration.

The newly developed sulphate detection system is described by Röthlisberger and others (2000). The detection principle is based on a standard photometric flow-injection method using methylthymol blue (MTB) (Madsen and Murphy, 1981) which was adapted to the existing CFA system. Thereby sulphate is indirectly determined by competitive reaction of MTB with barium ions. The resulting absorbance at $608 \mathrm{~nm}$ of MTB-barium complexes decreases as sulphate concentration increases.

The sensitivity of the sulphate determination is strongly affected by the quality of the MTB reagent and by the regularity of the various flow rates. The detection limit (calculated as three times the standard deviation of the baseline noise) is about $40 \mathrm{ng} \mathrm{g}^{-1}$, which is higher by up to a factor of four than the lowest concentration levels expected in Greenland ice. The maximum of the linear range of the calibration curve approaches $6000 \mathrm{ng} \mathrm{g}^{-1}$ and exceeds the maximum values of the measured samples by up to a factor of five. By evaluating multiple measurements on the same core section, we estimate the total uncertainty of a single data point selected out of the continuous record to be about $15 \%$, but at least $\pm 20 \mathrm{ng} \mathrm{g}^{-1}$, for concentrations $<130 \mathrm{ngg}^{-1}$. This is still above the typical uncertainty of around 10\% achieved for all other CFA detection systems described by Röthlisberger and others (2000). With a melting rate of approximately $3.5 \mathrm{~cm} \mathrm{~min}^{-1}$ and a temporal resolution of typically $20 \mathrm{~s}$ associated with the continuous sulphate signal (corresponding to the time needed to drop to $1 / \mathrm{e}$ of the signal of a sulphate standard solution measurement after switching back to blank), the characteristic depth resolution is estimated to be about $1 \mathrm{~cm}$.

Possible additional errors in the sulphate determination could be: (1) baseline distortion due to small uncontrollable flow-rate changes and due to flow interruption during valve switches, leading to transient systematic errors in both directions; (2) deviations from the required 1:1 molar ratio of MTB and barium in the reagent, causing a slightly smaller slope of the calibration curve for low sulphate concentrations which resulted in an underestimation for concentration levels $<200 \mathrm{ng} \mathrm{g}^{-1}$ and an overestimation for higher values; and (3) disproportionate occurrence of gaps in the dataset at low concentration levels due to unreliable readings close to the detection limit, leading to systematic higher overall means. A formal assessment of the sulphate data reliability, particularly at lower concentration levels, remains difficult at this stage. The same holds true for a realistic quantification of the uncertainties encountered. In more recent deployments of the CFA system, these systematic errors have been lowered by using non-linear calibration curves and by decoupling the automatic valve from the detection unit.

\section{Dating and data reduction}

Dating of the core has been based on the identification of well-known historic volcanic layers characterized, among other things, by high sulphate concentrations. Only the very distinct sulphate signals were used: Katmai, Alaska (AD 1912); Tambora, Indonesia (AD 1815); Laki, Iceland (1783 AD); Huaynaputina, Peru (AD 1600); unknown source (AD 1259); and Eldgja, Iceland (AD 934) (Fig. 2). On the other hand, annual-layer counting was also possible, due to the high depth resolution of the record, even though the annual snow accumulation is only around $100 \mathrm{~mm}$ w.e. $\mathrm{a}^{-1}$. A first criterion for setting annual marks is the increase of the calcium signal occurring around spring. In case of ambiguities, the typical winter to early-spring peak of the sodium signal was also used. The dating uncertainty between the reference horizons is estimated to be \pm 5 years.

Following Sommer and others (2000), the intervals between two annual marks were divided into 12 equidistant parts for which mean values from the included data points were calculated. In this way, CFA time series at a formal monthly resolution were generated.

Calculation of the sea-salt sulphate fraction by means of the sodium record gave on average a contribution to the total sulphate of only $8 \%$ during the pre-industrial epoch (this fraction is even lower in recent times). Here, we report total sulphate concentrations, i.e. without sea-salt correction.

\section{RESULTS AND DISGUSSION}

\section{Sulphate mean values and seasonal features}

Our sulphate CFA record is presented in Figure 2 at monthly resolution over the period from AD 830 to present. Sodium and calcium are also shown, because they are associated with the rather constant sea-salt and crustal sulphate sources. Sulphate shows the well-known anthropogenic increase in the course of the 20th century, and some very strong peaks obviously caused by volcanic deposits. In addition, the snow-accumulation rate as derived from annuallayer counting is shown in Figure 2. The long-term mean annual layer thickness $\lambda$ is fairly constant at $9.9 \pm 3.8 \mathrm{~cm}$ w.e. except for an excursion between AD 900 and 1300. A similar deviation can be seen in the accumulation-rate record from the NGT core B18 (Schwager, 2000), about $200 \mathrm{~km}$ south of B20, but not at other NGT positions. However, the long-term accumulation-rate changes are rather small and, according to the deposition model by Fischer and others (1998a), have only a minor influence on the mean sulphate concentrations (not more than 7\%). Other physical characteristics (e.g. elevation and distance from the coast) are negligible for this interior area of Greenland. 


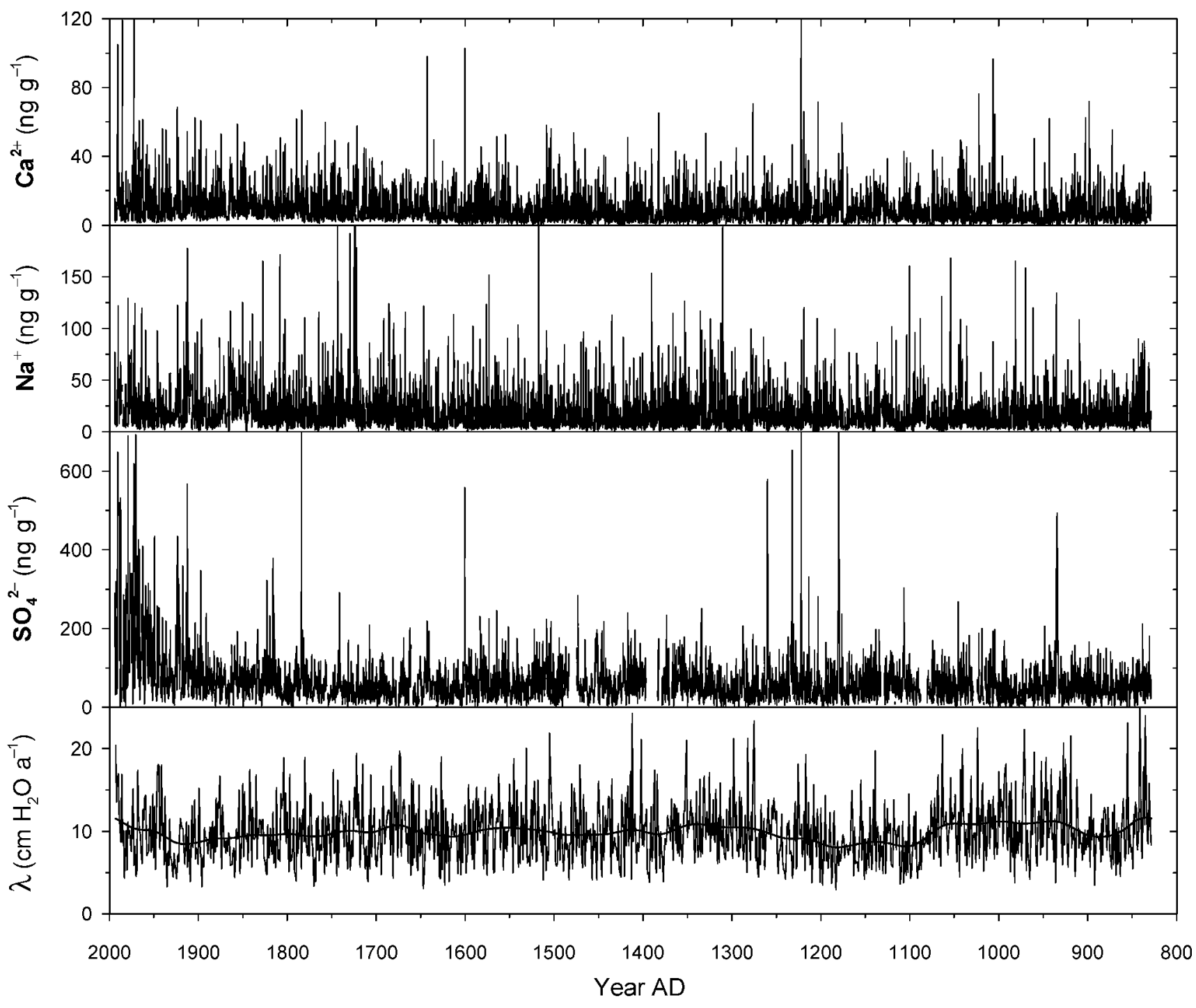

Fig. 2. Raw data of ion records at (formal) monthly resolution from B20 ice core from northeast Greenland. Annual layer thickness $\lambda$ has been smoothed by applying a low-pass filter (Gaussian filter with cut-off frequency of 100 years; bold line) to display long-term changes in the snow accumulation rate.

For comparisons of our mean sulphate values from the upper part of our core with those observed at Summit and North Greenland, the most prominent volcanic peaks were removed. It turned out that anthropogenic means (18501992) available from adjacent NGT cores (B18: $119 \mathrm{ng} \mathrm{g}^{-1}$; B20: $114 \mathrm{ng} \mathrm{g}^{-1}$; and B21: $114 \mathrm{ng} \mathrm{g}^{-1}$; values for B18 and B21 from Fischer and others, 1998b) are in perfect agreement, confirming that there are no analytical problems at higher concentration levels. A higher value with respect to Summit (67 ng g ${ }^{-1}$ : EUROCORE; personal communication from M. Legrand, 2001) can be fully explained by the difference in accumulation rates (Fischer and others, 1998a). In the preindustrial era back to AD 1500, however, the B20 mean data appear to be systematically higher by about $20 \%$ than those of adjacent NGT cores B18 and B21, even after correction of the small accumulation effect. The remaining systematic overestimation of low background sulphate values is likely to be explained by analytical effects of the CFA sulphate detection method as described above.

To illustrate in more detail the sulphate variability on the multi-annual scale, an expanded view is given in Figure 3, along with calcium (which has served as the main dating component) and the electrolytical conductivity. The sulphate noise level is obviously larger than the calcium one, particu- larly at lower concentrations. On the other hand, the electrolytical conductivity profile frequently corresponds to the sulphate variability even at lower levels. This indicates a possible overestimation of the detection limit given above as $40 \mathrm{ng} \mathrm{g}^{-1}$. Furthermore the periodically occurring sulphate peaks, found in the range of up to $200 \mathrm{ng} \mathrm{g}^{-1}$ almost every year concurrently with the annual calcium peaks, suggest a persistent reliable seasonal sulphate signal can be detected with CFA. Note that no clear volcanic event was identified in the core section shown in Figure 3.

In order to evaluate the seasonal timing of the sulphate signal, we used our formal monthly values as described above. Because the accumulation distribution in the course of the year is not the same for each year, we stacked the individual months over long pre-industrial and industrial time intervals, respectively, to minimize the uncertainties (for details and accuracy of this method see Sommer and others, 2000). Note, however, that this method cannot account for a systematic seasonal bias in the annual cycle of snow accumulation, so each interval does not truly represent a single month. The adjustment of these formal months to calendar months was accomplished by setting the marks in the increasing calcium flank as February. Figure 4 illustrates mean seasonal cycles of sulphate for the industrial 
Year $A D$

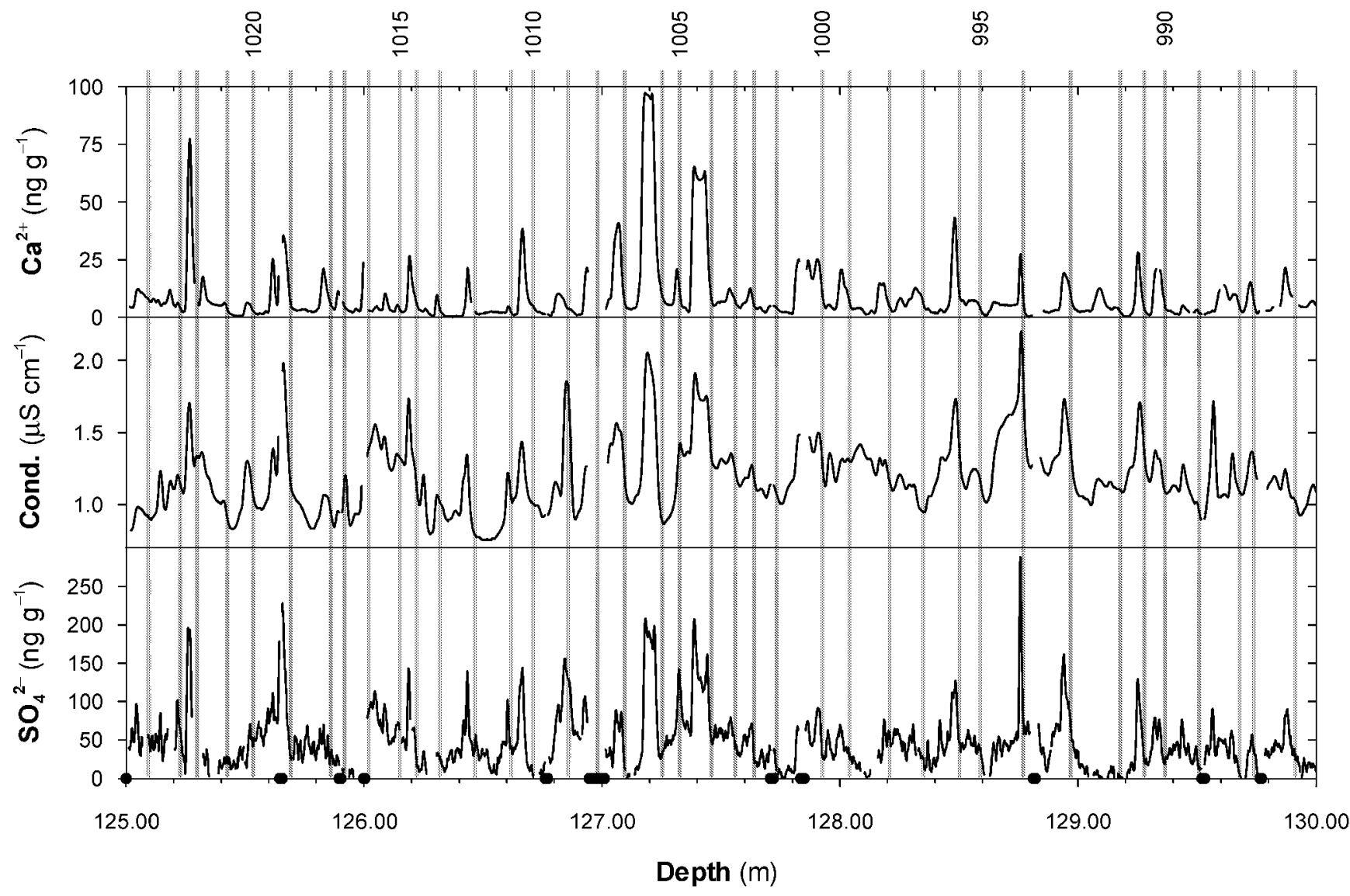

Fig. 3. Expanded view on a B20 core section. Vertical bars indicate annual layering used for dating; dots at the depth scale indicate core breaks.
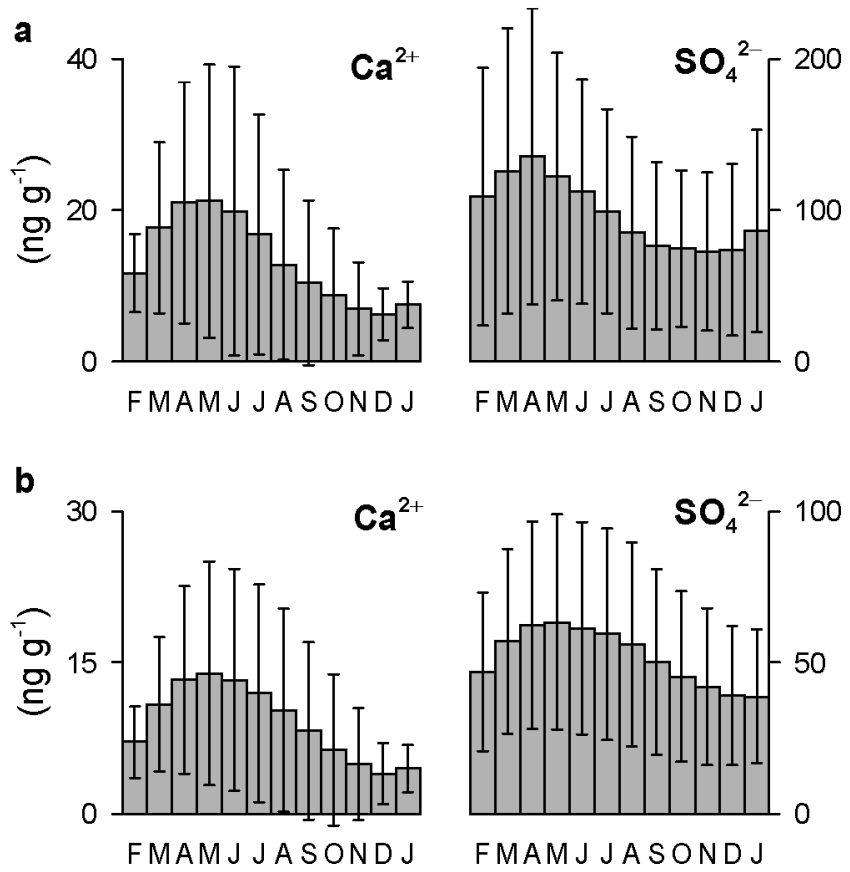

Formal month

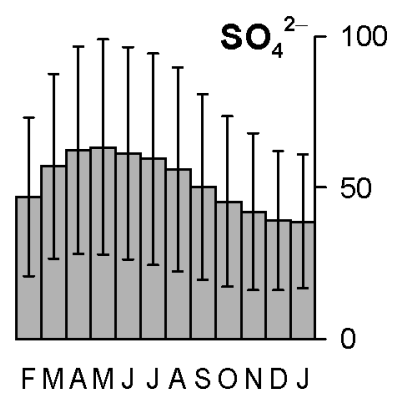

Formal month

Fig. 4. Mean annual cycles of calcium and sulphate observed in B20 ice core (a) for the industrial era AD 1850-1994, and (b) for the pre-industrial era $A D$ 830-1850. Bars correspond to a $1 \sigma$ standard error.

and pre-industrial eras, along with calcium serving as the seasonal reference species. These seasonal cycles are in good agreement with the present state of knowledge. At higher sulphate levels during the industrial era (Fig. 4a), the seasonality is mainly driven by the Arctic haze, leading to a sulphate maximum during spring (Laj and others, 1992; Whitlow and others, 1992; Dibb and Jaffrezo, 1997). At lower sulphate levels in pre-industrial epochs, the extension of this peak towards summer (Fig. 4b) is consistent with the findings of Legrand and others (1997) reported for a short 11 year period around AD 1200, though at much lower time resolution. It appears that the main feature of seasonal cycles can be reliably reproduced, although we may expect the seasonal amplitude to be biased by an analytical systematic overestimation of sulphate minima, particularly during the pre-industrial core section with lower mean values.

We may summarize that systematic effects, particularly at lower sulphate levels, lead to an overestimation of overall mean values. The highly resolved sulphate, however, captures main features such as the typical seasonality quite well. It is not yet known whether weak long-term changes in the pre-industrial era might also be resolved.

\section{Examination of episodic sulphate events}

The examination of episodic volcanic events is a straightforward application of a sulphate record at sub-annual resolution. Due to associated high concentration levels, the analytical inaccuracy is of minor importance here. Different types of volcanic events are presented in Figure 5. 


\section{Year AD}
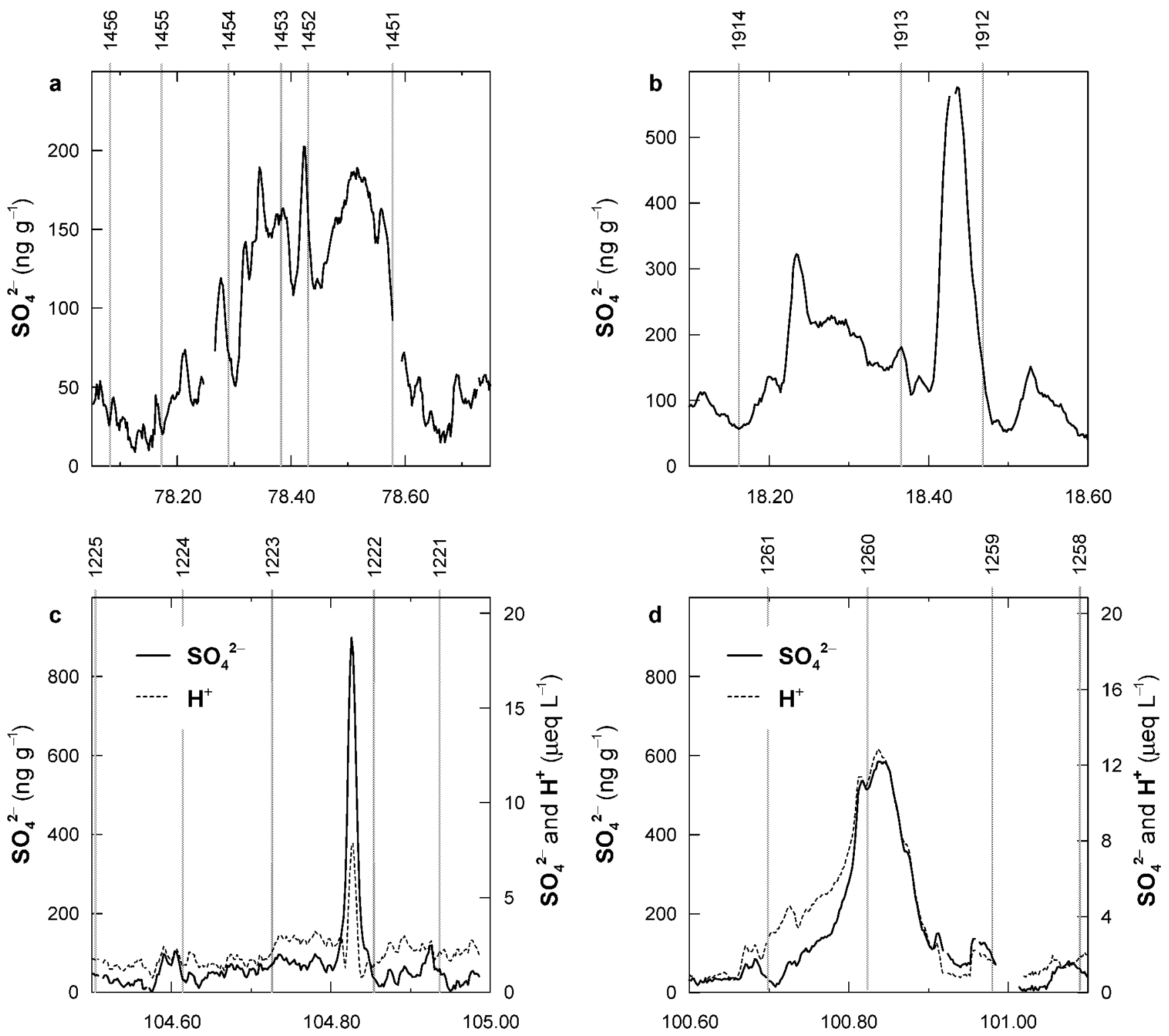

\section{Depth $(m)$}

Fig. 5. Examples of distinct sulphate peaks from B20 ice core at sub-seasonal resolution: (a) multi-annual feature possibly from Kuwae (AD $1452 \pm 10)$; ( b) Katmai ( AD 1912) possibly followed by Hekla ( AD 1913); (c) short-pulse feature, possibly from Hekla (AD 1222) or Reykjaneshryggur (AD 1223); (d) unknown source ( AD 1259) with bipolar occurrence. The $H^{+}$concentration is derived from the ion-balanced CFA components (for explanations see text).

Figure 5 a shows a broad peak over several years, probably representing the huge Kuwae eruption (volcanic explosivity index (VEI) 6) which occurred in AD $1452 \pm 10$ in the southwest Pacific region (Simkin and Siebert, 1994). The typical input from stratospheric material during spring and summer (Beer and others, 1991) shows up for another 3 years after the major event. Following Simkin and Siebert (1994), this event is possibly overlaid by another eruption that occurred in the same time period (Aniakchak, Alaska, VEI 5, 1450?).

In Figure 5b the potential of resolved sub-annual structures is demonstrated since two eruptions fit the two peaks appearing in AD 1912 and 1913: Katmai, Alaska (VEI 6, starting on 6 June 1912), and afterwards Hekla, Iceland (VEI 2, starting on 25 April 1913). A Mexican eruption in January 1913 is the only other significant one known in this time period.
A spike of very short sub-annual duration is presented in Figure 5c. Most likely it was produced from the AD 1222 eruption of Hekla or the AD 1223 eruption of the submarine Reykjaneshryggur, Iceland (VEI 2). The short distance to Greenland suggests that the accompanying extraordinary calcium spike reaching $140 \mathrm{ngg}^{-1}$ might be related to volcanic-ash deposits. Because of the almost identical depth resolution of the other CFA components, concurrent peaks are emphasized. For this purpose the $\mathrm{H}^{+}$concentration was derived from the ion balance (driven here by the major species sulphate and calcium) of CFA components. Missing $\mathrm{Cl}^{-}, \mathrm{Mg}^{2+}$ and $\mathrm{K}^{+}$contributions were inferred from $\mathrm{Na}^{+}$ assumed to be totally marine and from $\mathrm{Ca}^{2+}$ assumed to be totally crustal-derived. $\mathrm{H}^{+}$gave a relatively low value for this event (see Fig. 5c) which might not show up in an ECM record (Clausen and others, 1997). 


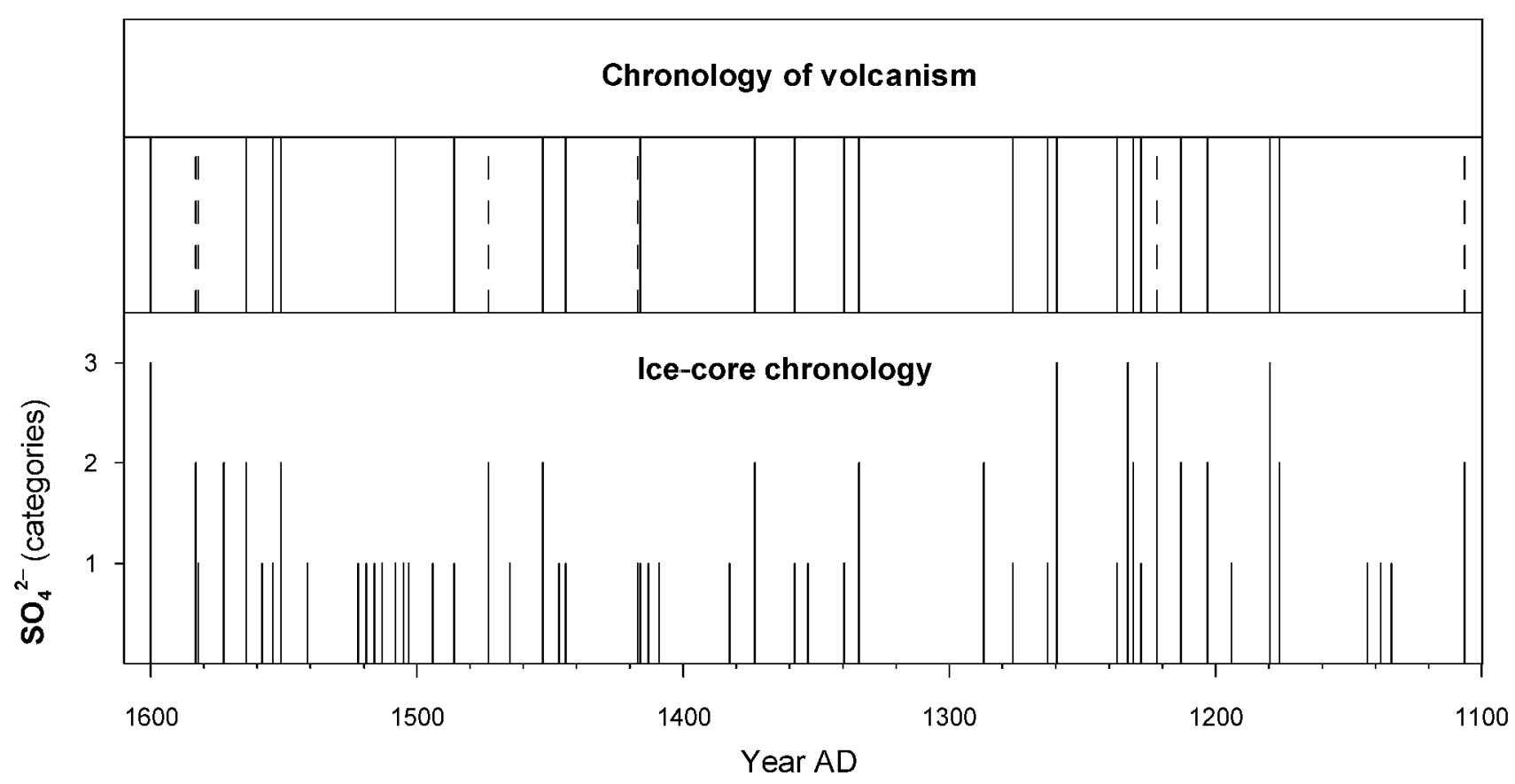

Fig. 6. Comparison of volcanic ice-core events from B20 arranged according to three categories (for details see text) with a chronology of volcanism. Full lines indicate obvious assignments, and dashed lines ambiguous ones.

A prominent volcanic event also seen in many other ice cores from Greenland and Antarctica is the eruption of an unknown source in AD $1259 \pm 10$ (Fig. 5d). Because no outstanding input of calcium occurred at the same time, the estimated $\mathrm{H}^{+}$profile closely follows the sulphate signal at a micro-equivalent ratio near unity. The high depth resolution not only helps to distinguish more clearly between adjacent events, but also allows accurate calculation of inventories in $\mathrm{kg}$ sulphate $\mathrm{km}^{-2}$. We calculated an inventory of a volcanic event as the integral over the sulphate peak minus the prevailing mean background concentration weighted with the particular mean density at this depth. Integral limits are the feet of the volcanic peak where the sulphate concentration values exceed the mean background level. We estimated the inventories of the AD 1259 event and the AD 1912 Katmai eruption to be 41 and $10 \mathrm{~kg} \mathrm{~km}^{-2}$, respectively, which are noticeably lower values than those from Summit based on ECM records (161 and $15 \mathrm{~kg} \mathrm{~km}^{-2}$, respectively, for GRIP; Clausen and others, 1997) or on biannual sulphate records (145 and $27 \mathrm{~kg} \mathrm{~km}^{-2}$, respectively, for GISP2; Zielinski, 1995). One reason for this may be better determination of the peak feet, and thus a clearer separation of a volcanic event from the background level, due to a highresolution sulphate dataset. But the main reason for discrepancies in the inventory values seems to be spatial deposition differences which need to be carefully assessed when, for example, the optical depth of the atmosphere based on icecore data is calculated.

\section{Refined volcanic chronology}

Another application of high-resolution sulphate records leads to a refined volcanic chronology. To explore this possibility, we first compiled a list of possible volcanic ice-core events

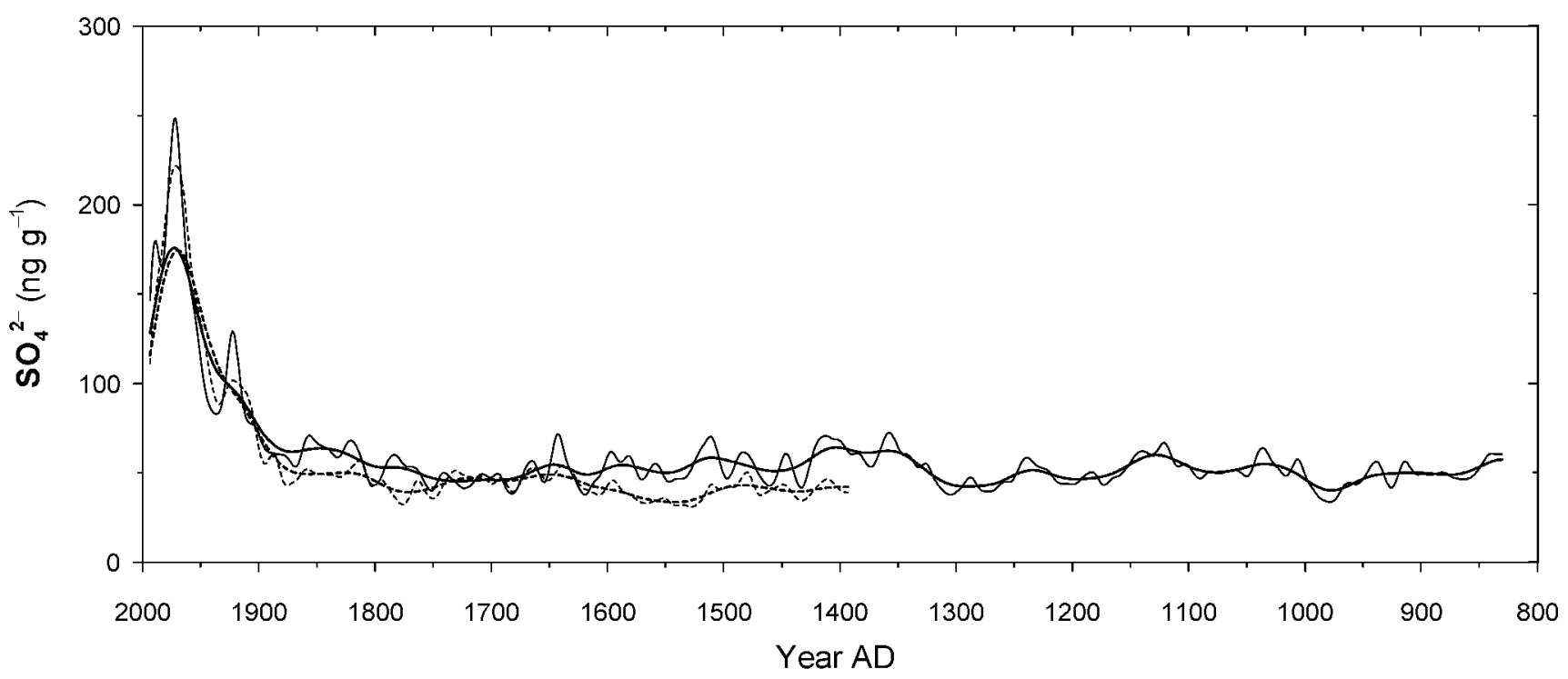

Fig. 7. Low-pass filtered sulphate records from B20 (solid lines) and from B21 (dashed lines). Bold lines correspond to 100 year, thin lines to 30 year cut-off frequencies of the Gaussian filter. 
during the time period AD 1100-1600 according to three different categories (see Fig. 6, lower plot): peaks with non-seasalt sulphate values of (1) $150-200 \mathrm{ng} \mathrm{g}^{-1}$, (2) $200-400 \mathrm{ng} \mathrm{g}^{-1}$ and $(3)>400 \mathrm{ng} \mathrm{g}^{-1}$. Then we independently picked out from Simkin and Siebert (1994) all listed eruptions with a VEI $\geqslant 5$ (including Plinian ones), all Northern Hemispheric eruptions with a VEI of 4, all Icelandic eruptions in view of their geographical proximity, and all unknown sources detected in other ice cores. From this list we eliminated all eruptions showing a dating uncertainty of $> \pm 10$ years. Subsequently we assigned our ice- core candidates to the literature-based list. If the assignment was consistent with the maximum dating uncertainty of \pm 5 years, we marked it in Figure 6 in the upper plot with a vertical line; if the assignment was ambiguous we indicated this with a dashed line. Nearly $60 \%$ of our candidates have been assigned, and about $45 \%$ of the events from the literature-based list have been hit. Different assignment qualities showed up for different time periods: a relatively good agreement was found for AD 1150-1400 but a poor one around AD 1500 . Noticeable is the 120 year period of more frequent stronger events around AD 1200.

A high-resolution sulphate record leads to a refined volcanic chronology since even very narrow volcanic spikes can be recognized as the relatively accurately dated Icelandic volcanoes. Compared to ECM profiling, the advantages of direct sulphate analyses are the low risk of interference from concurrent species and the more accurate calibration procedure in terms of volcanic sulphate.

\section{Long-term sulphate changes}

To extract long-term sulphate variations from B20 in the pre-industrial era, we looked at strongly smoothed sulphate records over the entire period. We removed strong episodic sulphate peaks in categories 2 and 3 according to the procedure presented above, and calculated annual means which were low-pass filtered afterwards (Gaussian filter with cut-off frequencies of 30 and 100 years, respectively).

For comparison we used the same filter procedures on annually resolved raw data from B21 (Fischer and others, 1998b) in which episodic events have already been removed. Figure 7 shows the long-term variations of both cores: B20 which reaches back to AD 830, and B21 which covers the more recent period starting in $\mathrm{AD} 1400$. The deviation between the two records is comparable to the variability seen within the extended B20 period back to AD 830. We thus conclude that the observed long-term changes over the first half of the last millennium may not be significant with respect to the stated analytical precision of the CFA sulphate method, nor to the typical glacio-meteorological noise demonstrated by Fischer and others (1998b) for ice-core records in the NGTarea. Note that this assessment holds true for the background sulphate record only where we eliminated volcanic events in advance of low-pass filtering. As in the previous section (see Fig. 6), we noticed a 120 year period around AD 1200 with frequent strong sulphate peaks mainly identified as volcanic horizons. This suggests higher atmospheric sulphate loads during this period, though they are a highly episodic feature.

\section{ACKNOWLEDGEMENTS}

The ice core was recovered by the Alfred Wegener Institute (AWI), Bremerhaven, Germany, in the frame of the NGT project. The analyses have been supported by the Swiss National Science Foundation, the Bundesamt für Bildung und Wissenschaft and the University of Bern. We thank B. Mieding (AWI, Bremerhaven) and M. Legrand (Laboratoire de Glaciologie et Géophysique de l'Environnement, Grenoble, France) for providing data.

\section{REFERENGES}

Beer, J. and 15 others. 1991. Seasonal variations in the concentrations of ${ }^{10} \mathrm{Be}$, $\mathrm{Cl}^{-}, \mathrm{NO}_{3}{ }^{-}, \mathrm{SO}_{4}{ }^{2-}, \mathrm{H}_{2} \mathrm{O}_{2},{ }^{210} \mathrm{~Pb},{ }^{3} \mathrm{H}$ mineral dust and $\delta^{18} \mathrm{O}$ in Greenland snow. Atmos. Environ., Ser. A, 25(5-6), 899-904.

Clausen, H. B. and 6 others. 1997. A comparison of the volcanic records over the past 4000 years from the Greenland Ice Core Project and Dye 3 Greenland ice cores. 7. Geophys. Res., 102(C12), 26,707-26,723.

Dibb, J. E. and J.-L. Jaffrezo. 1997. Air-snow exchange investigations at Summit, Greenland: an overview. F. Geophys. Res., 102(C12), 26,795-26807.

Fischer, H., D. Wagenbach and J. Kipfstuhl. 1998a. Sulfate and nitrate firn concentrations on the Greenland ice sheet. 1. Large-scale geographical deposition changes. 7. Geophys. Res., 103(D17), 21,927-21,934.

Fischer, H., D. Wagenbach and J. Kipfstuhl. 1998b. Sulfate and nitrate firn concentrations on the Greenland ice sheet. 2. Temporal anthropogenic deposition changes. F. Geophys. Res., 103(D17), 21,935-21,942.

Laj, P., J. M. Palais and H. Sigurðsson. 1992. Changing sources of impurities to the Greenland ice sheet over the last 250 years. Atmos. Environ., 26. A(14), 2627-2640.

Legrand, M. and 6 others. 1997. Sulfur-containing species (methanesulfonate and $\mathrm{SO}_{4}$ ) over the last climatic cycle in the Greenland Ice Core Project (central Greenland) ice core. F. Geophys. Res., 102(C12), 26,663-26,679

Madsen, B. C. and R. C. Murphy. 1981. Flow injection and photometric determination of sulphate in rainwater with methylthymol blue. Anal. Chem., 53(12), 1924-1926.

Mayewski, P. A., W. B. Lyons, M. J. Spencer, M. S. Twickler, C. F. Buck and S. Whitlow. 1990. An ice core record of atmospheric response to anthropogenic sulphate and nitrate. Nature, 346(6284), 554-556.

Mayewski, P. A. and 6 others. 1997. Major features and forcing of high-latitude Northern Hemisphere atmospheric circulation using a 110,000year-long glaciochemical series. J. Geophys. Res., 102(C12), 26,345-26,366.

Neftel, A., J. Beer, H. Oeschger, F. Zürcher and R.C. Finkel. 1985. Sulphate and nitrate concentrations in snow from south Greenland, 1895-1978. Nature, 314(6012), 611-613.

Röthlisberger, R. and 6 others. 2000. Technique for continuous high-resolution analysis of trace substances in firn and ice cores. Environ. Sci. Technol., 34(2), 338-342.

Schwager, M. 2000. Ice core analysis on the spatial and temporal variability of temperature and precipitation during late Holocene in North Greenland. (Ph.D. thesis, University of Bremen. Alfred Wegener Institute for Polar and Marine Research.

Simkin, T. and L. Siebert. 1994. Volcanoes of the world. Second edition. Tucson, AZ, Geoscience Press.

Sommer, S., D. Wagenbach, R. Mulvaney and H. Fischer. 2000. Glaciochemical study spanning the past $2 \mathrm{kyr}$ on three ice cores from Dronning Maud Land, Antarctica. 2. Seasonally resolved chemical records. $\mathcal{f}$. Geophys. Res., 105(D24), 29,423-29,433.

Whitlow, S., P. A. Mayewski and J. E. Dibb. 1992. A comparison of major chemical species seasonal concentration and accumulation at the South Pole and Summit, Greenland. Atmos. Environ., 26A(11), 2045-2054.

Zielinski, G. A. 1995. Stratospheric loading and optical depth estimates of explosive volcanism over the last 2100 years derived from the Greenland Ice Sheet Project 2 ice core. 7. Geophys. Res., 100(D10), 20,937-20,955

Zielinski, G. A. and 8 others. 1994. Record of volcanism since 7000 B.C. from the GISP2 Greenland ice core and implications for the volcano-climate system. Science, 264(5161), 948-952. 